\title{
A RESTINGA COMO EXEMPLO DE ECOSSISTEMA E A SUA URBANIZAÇÃO SUBSÍDIOS PARA POSSÍVEIS INTERVENÇÕES
}

ROSANA MOREIRA DA ROCHA

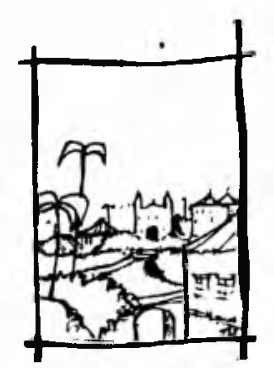

Até há pouco tempo a palavra ecossistema só fazia parte do vocabulário especializado, a ponto de não existir como verbete em dicionários conceituados da língua portuguesa. Mesmo como termo técnico, a palavra é bastante recente. Até a década de 40 , os ecologistas dedicavam-se principalmente ao estudo das comunidades biológicas, mas a partir desta época perceberam que estas comunidades e seu meio ambiente deveriam ser considerados juntos em uma única unidade, pois formavam um outro nível de organização. O termo ecossistema, para este novo nível de organização, foi proposto primeiramente em 1935 pelo ecologista britânico A. G. Tansley. O conceito da unidade entre seres vivos e seu ambiente não era novo, entretanto, remontando aos mais antigos registros da história escrita.

Mais recentemente, os pesquisadores J. Lovelock e L. Margulis (1973, 1974, 1975, 1979) escreveram uma série de artigos onde defendem a Hipótese de Gaia, segundo a qual os organismos não seriam simplesmente moldados por seu ambiente físico-químico, mas também atuariam neste ambiente adaptando-o às suas necessidades. Estes autores levaram a idéia de ecossistema ao extremo, argumentando que os organismos evoluíram com seu meio ambiente, formando um sistema complexo de controle, o qual mantém as condições da Terra favoráveis à vida.

Com a preocupação ambientalista em crescimento e a necessidade de manejo e proteção dos ecossistemas, novos aspectos foram colocados em evidência. $\mathrm{O}$ conhecimento sobre os mecanismos de funcionamento dos ecossistemas, dos fluxos de matéria e energia, e dos graus de intervenção que eles podem suportar passaram a ter uma grande importância.

Dois processos são essenciais à manutenção dos seres vivos: alimentação e reprodução. A alimentação fornece a energia necessária à sobrevivência do indivíduo e a reprodução promove a manutenção da espécie no tempo. Cada espécie representa uma combinação única de características, originando um sistema in- 
tegrado e eficiente em seu meio ambiente. A interação entre espécies em uma relação de presa-predador estabelece uma teia alimentar que permite o fluxo de energia e de matéria entre todos os componentes do ecossistema.

Vale à pena lembrar aqui que praticamente toda a energia presente no compartimento orgânico da biosfera é proveniente da fotossíntese que é o processo de transformação de energia luminosa em energia química através da produção de açúcar. Este processo é realizado unicamente pelos organismos portadores do pigmento verde clorofila, que são em sua maioria as plantas no ambiente terrestre e as algas no mar. Estes organismos são, por isso, chamados produtores e são eles que controlam a quantidade de energia introduzida em todos os ecossistemas. Ao longo de uma cadeia alimentar, a energia é gradualmente dissipada, pois é consumida pelo metabolismo de cada organismo e perdida na forma de calor. A própria aquisição de energia pelos seres vivos não é um processo totalmente eficiente, pois nem todo o alimento pode ser digerido e aproveitado. Portanto, a quantidade de energia existente em um determinado ecossistema é um fator limitante à quantidade de vida que o mesmo pode manter e daí a preocupação que se deve ter com a manutenção de uma cobertura vegetal mínima saudável e produtiva capaz de gerar alimento suficiente para os organismos daquele ecossistema e, em última instância, para garantir a nossa própria sobrevivência.

Ao contrário do que ocorre com a energia, os materiais utilizados na produção de matéria orgânica não se perdem ao longo da cadeia alimentar. Eles são reaproveitados dentro do próprio corpo dos animais consumidores ou decompostos em partículas mais simples por organismos decompositores, em seguida são incorporados ao meio ambiente (no solo ou na água) e novamente aproveitados pela vegetação na confeç̧ão de matéria orgânica. Este ciclo é encontrado em ecossistemas íntegros, mas pode ser quebrado pela falta de algum elo importante do ciclo, acarretando a diminuição do material disponível aos seres vivos. Em alguns ecossistemas, como as florestas tropicais e os recifes de coral, o ciclo da matéria ocorre quase que integralmente dentro do compartimento biológico do ecossistema, isto é, os organismos atuam como reservatórios de matéria e, se este ciclo é rompido, a matéria se perde definitivamente para o meio ambiente e dificilmente é recuperada. É o que ocorre em solos desmatados de florestas, cujos nutrientes são perdidos através da lixiviação pela água de chuva porque não estão sendo absorvidos pela vegetação.

Organismos que não mantêm uma interação direta de predador-presa entre si, geralmente interagem indiretamente através do processo de competição. Ocorre competição sempre que um mesmo recurso ambiental, seja ele alimento, local para abrigo, local de procriação, espaço e luz no caso das plantas, é disputado por mais de uma indivíduo. Se uma determinada espécie de águia, por exemplo, 
tem sua população diminuida devido a um ano desfavorável (pouca quantidade de alimento, por exemplo) ou à caça seletiva, a população de um outro pássaro do qual ela se alimenta será favorecida e tenderá a aumentar, podendo então entrar em competição com uma terceira espécie de ave que também constrói ninhos em ocos de árvores, recurso este que se tornará limitado.

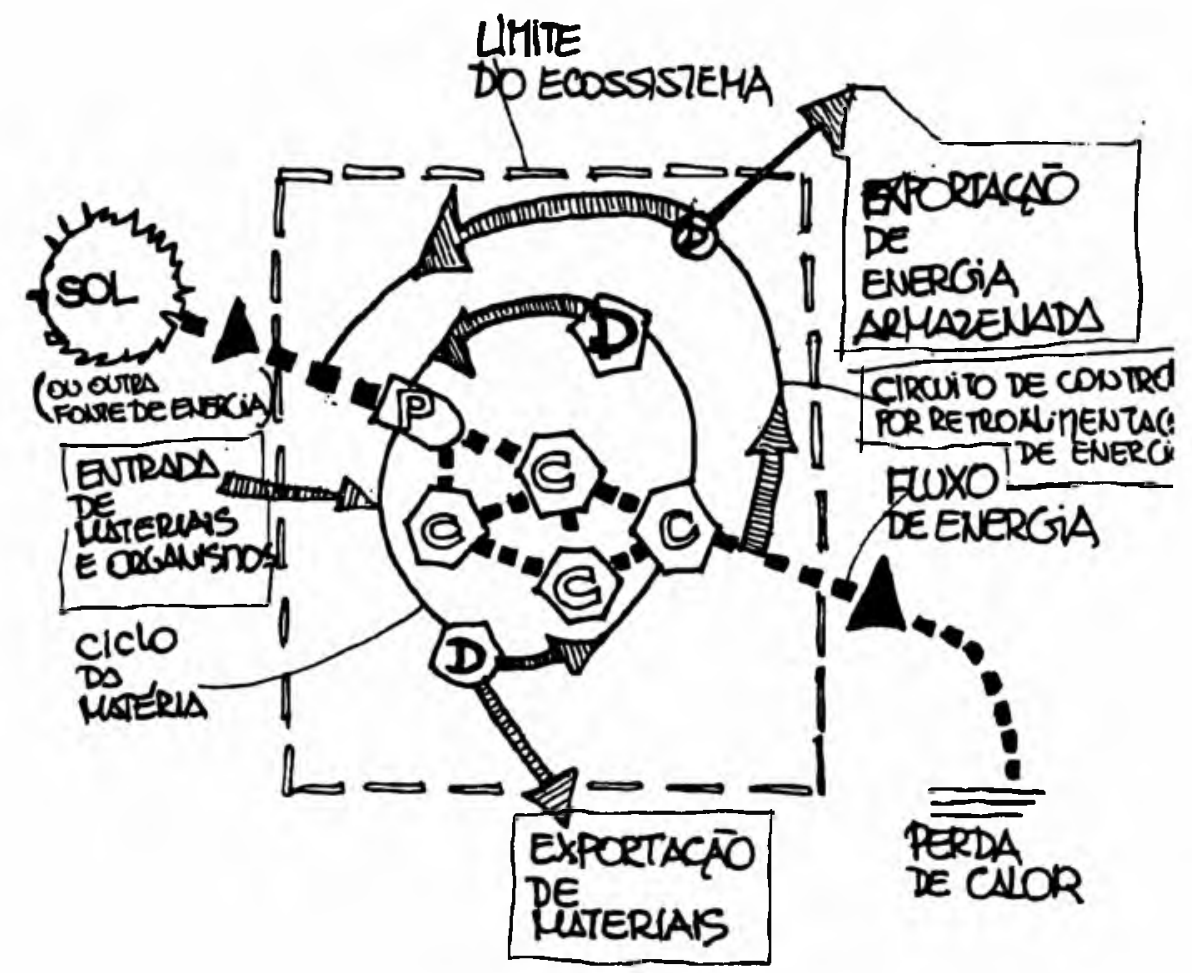

Fig. 1 Esquema exemplificando os componentes de um ecossistema $(P=$ produtores, $\mathrm{C}=$ consumidores, $\mathrm{D}=$ depositos de matéria e energia), o fluxo de energia e o ciclo da matéria através destes componentes (segundo Odum, 1985)

Este processo exemplifica de que maneira se fazem as ligações aparentemente invisíveis entre todos os componentes do ecossistema sejam eles biológicos ou não. É possível concluir que a malha de interações é praticamente infinita e que colocar limites geográficos ou de elementos constituintes para os ecossistemas é uma atividade subjetiva, uma abstração humana para tornar mais prático o seu estudo. Todo ecossistema é necessariamente um sistema aberto, pois existe troca de energia, matéria e mesmo de espécies com outros ecossistemas adjacentes. Sendo assim, no estudo do manejo de um ecossistema é fundamental considerar também os ambientes de entrada e de saída.

No início do século, os primeiros ecólogos acreditavam que as comunidades e, por consequência, os ecossistemas eram "superorganismos" isto é, apresentavam componentes próprios (as espécies), interdependentes, com um processo evolutivo característico e propriedades emergentes típicas do nível de comuni- 
dade e não explicadas pela soma das propriedades das espécies. Estudos posteriores, entretanto, mostraram que a maioria das espécies não são exclusivas de uma determinada comunidade, que a comunidade evolui, mas não sempre do mesmo modo, e que esta evolução pode ser um processo altamente imprevisível. O que existe, na verdade, são coleções de espécies com requisitos ambientais semelhantes e que, por isso, se associam em um determinado local; as interações que passam a existir entre estas espécies criam realmente propriedades emergentes como a fisionomia, a diversidade e a produtividade, que são próprias de uma comunidade. Não existem limites espaciais bem definidos para uma comunidade, pois o que ocorre geralmente é um gradiente ambiental (variação gradual das características do meio ambiente) sobre o qual as espécies se substituem, formando em determinados locais associações típicas. Somente nos casos em que existe uma mudança ambiental abrupta, como uma região com afloramento de minério onde o solo se modifica drasticamente, ou onde houve uma degradação antrópica intensa, para citar apenas dois exemplos, podemos encontrar um limite bem preciso na distribuição das espécies (Odum, 1985).

Neste trabalho trataremos da restinga como exemplo de ecossistema, constituído de diversas comunidades que se substituem dentro do mesmo, sem limites definidos entre elas. $O$ próprio limite espacial da restinga no seu lado continental também é de difícil definição, na medida em que ela se integra com a floresta interior. Apesar de se tratar de um ecossistema terrestre, a restinga apresenta uma ligação muito estreita com o ambiente marinho e não pode ser desvinculada deste.

\section{CARACTERÍSTICAS DAS RESTINGAS}

Sobre os litorais oriental e meridional brasileiro formaram-se extensas planícies sedimentares arenosas que, em conseqüência das transgressões e regressões marinhas, tomaram a forma de uma sucessão de cordōes litorâneos arenosos. Estas formações são recobertas por uma vegetação característica que os índios denominavam de "nhundu" ou "jundu" isto é, vegetação adjacente à praia. Ao conjunto de formações geomorfológicas e às diferentes comunidades biológicas que as ocupam dá-se o nome genérico de restingas (Lacerda, Araujo, 1987).

As restingas, no entanto, estão longe de constituírem uma formação uniforme ao longo da costa brasileira. No norte do Espírito Santo e no Rio de Janeiro formaram-se largas planícies. Em outros trechos, as restingas isolaram do mar grandes lagunas, como Araruama (RJ) ou a Lagoa dos Patos (RS). No sul do estado de São Paulo elas formaram ilhas próximas à costa como a Ilha Comprida e a Ilha do Cardoso que delimitam um grande complexo estuarino-lagunar. Esta variedade geomorfológica também permitiu o estabelecimento de comunidades vegetais e animais muito diversificadas (Lacerda et al., 1984). 


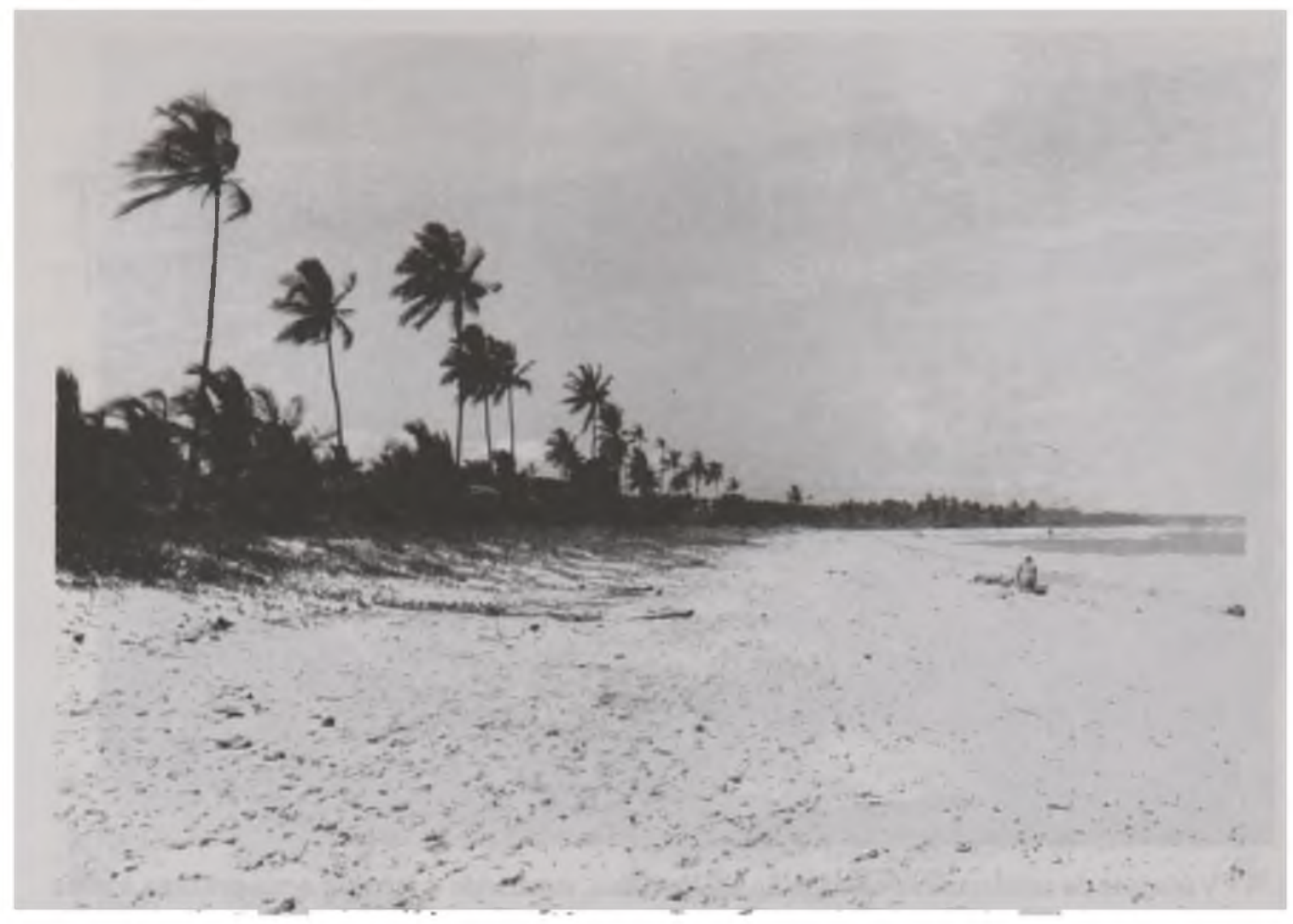

Fig. 2 - Faixa de restinga mais próxima à praia, recobrindo a duna primária

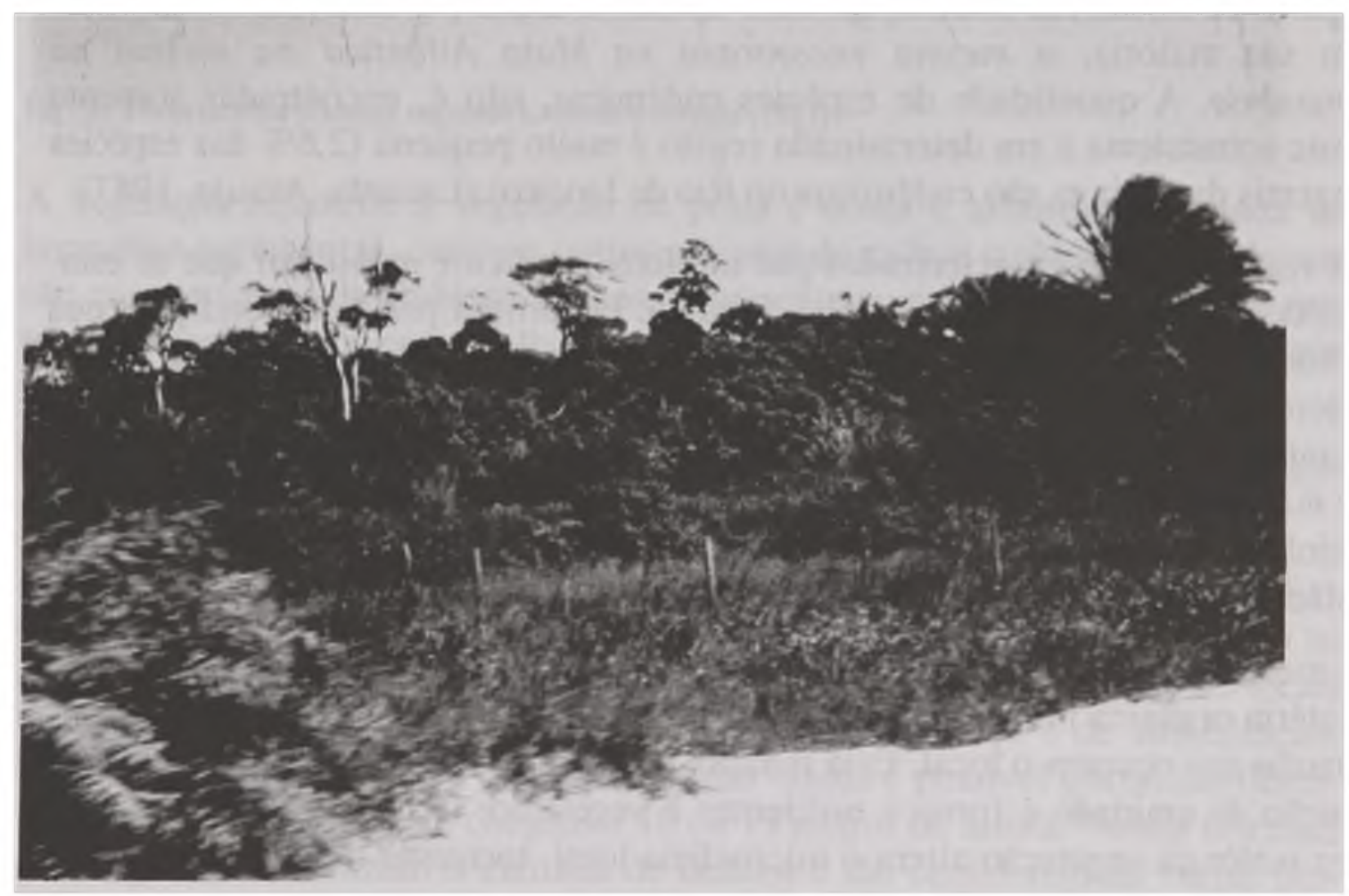

Fig. 3 - Restinga baixa arbustiva próxima à praia, em Nova Viçosa, BA 


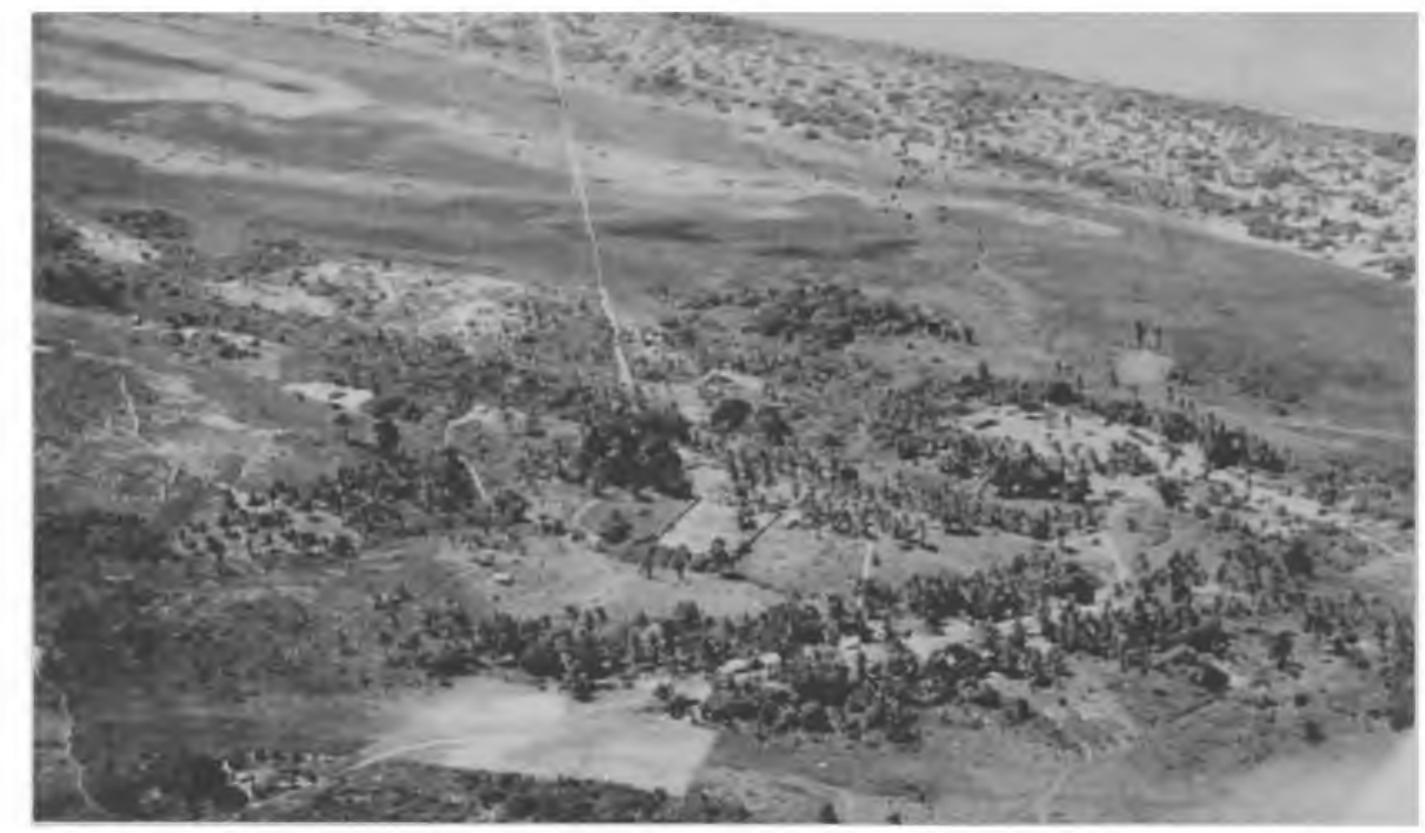

Fig. 4 - Variedade de ambientes na restinga ao sul da Bahia, mostrando a faixa de areia próxima à praia recoberta pela vegetação e lagoas interiores

Apesar de formarem associações bem típicas, a fauna e a flora das restingas é, em sua maioria, a mesma encontrada na Mata Atlântica ou mesmo na Amazônia. A quantidade de espécies endêmicas, isto é, encontradas somente neste ecossistema e em determinada região é muito pequena (2,6\% das espécies vegetais da restinga são endêmicas no Rio de Janeiro) (Lacerda, Araujo, 1987).

As restingas estão caracterizadas por um forte gradiente ambiental que se estabelece perpendicularmente à linha de praia. Próximo à praia, as condições que predominam são: solo arenoso, quase sem matéria orgânica, altamente salino, microclima quente e seco e alta luminosidade. Nesta região ocorrem somente plantas bem baixas e rasteiras, cujos caules rastejantes permitem que as mesmas se mantenham na superfície do solo que é muito móvel. Apresentam adaptações fisiológicas e morfológicas para suportar a alta salinidade do ambiente e suas raízes são superficiais para captar rapidamente a água de chuva.

À medida em que penetramos em direção ao interior, aumenta a quantidade de matéria orgânica no solo devido à própria decomposição de partes mortas das plantas que ocupam o local. Esta matéria orgânica acumulada favorece a manutenção de umidade e fornece nutrientes à vegetação. $O$ desenvolvimento cada vez maior da vegetação altera o microclima local, tornando o ar menos quente, mais úmido e o solo mais sombreado. 


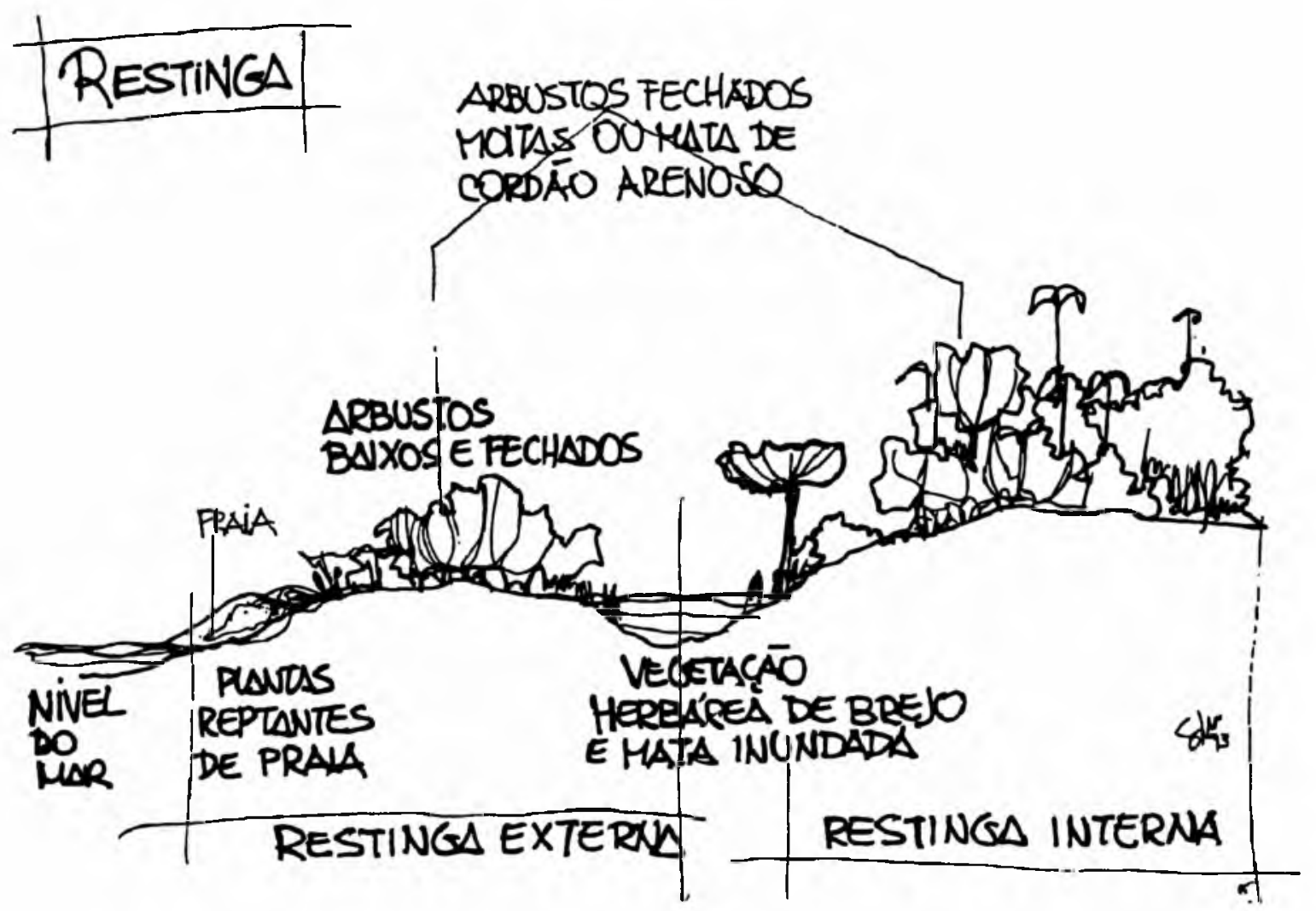

Fig. 5 - Perfil de uma restinga segundo Lacerda e Araujo (1987)

A vegetação adjacente à vegetação de praia é densa e arbustiva, formada de bromélias espinhentas, cactos e outros arbustos de galhos rígidos. Estas plantas são características de ambientes secos e apresentam várias adaptações para restringir a perda d'água como folhas transformadas em espinhos ou recobertas por cutícula espessa e estruturas de armazenamento de água.

Esta zona é logo sucedida por uma mata baixa de restinga em lugares mais preservados ou por uma comunidade de moitas e clareiras.

Muitas vezes, entre os cordões arenosos depositados paralelamente à praia, formam-se depressões, ocupadas por longas e estreitas lagoas ou brejos, devido ao afloramento do lençol freático. Nestas formações predominam plantas de locais úmidos e os animais as utilizam para construção de ninhos e de alimentação. Tanto nas depressões como nas margens das lagoas é possível encontrar florestas bem desenvolvidas que chegam a 10 ou 15 metros de altura. Nestas florestas o solo já tem uma razoável camada de detritos e são características certas bromélias de chão e palmeiras, como o palmito. 


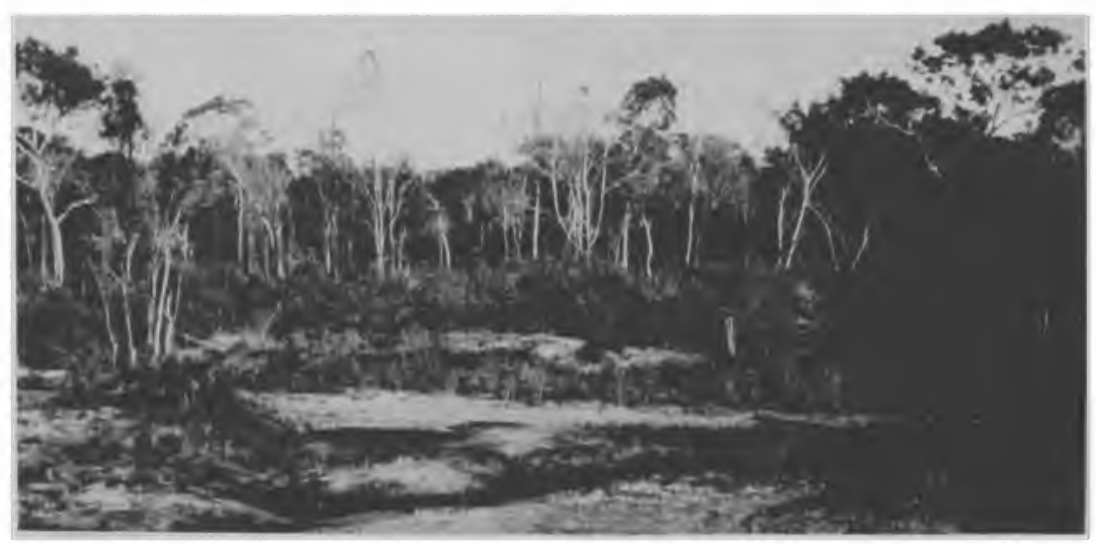

Fig. 6 - Área de restinga baixa arbustiva e de restinga alta arborea

Após esta região alagada, diferentes formações vegetais podem recobrir o cordão mais interno da restinga. No Rio de Janeiro predomina uma vegetação baixa formada pela associação de plantas resistentes ao fogo. Em outras regiōes menos alteradas pela ação humana, a vegetação pode ser mais alta e mais robusta, intercalada por clareiras. Em ambos os casos, as plantas têm características xeromórficas (adaptações ao ambiente seco).

Pela descrição anterior pode-se observar que $o$ gradiente ambiental forma faixas paralelas à costa com condições ambientais semelhantes e que abrigam comunidades razoavelmente definidas.

Em todas estas comunidades, em maior ou menor grau, os produtores pouco dependem do solo como fonte de nutrientes. Os borrifos da água do mar, trazidos pelo vento na forma de maresia, é que suprem as necessidades das plantas. Neste aspecto, as plantas epífitas (que crescem sobre outras plantas) e, dentre elas, principalmente as bromélias, têm um papel primordial na captação dos nutrientes e na transferência destes ao resto da vegetação. As bromélias absorvem água e nutrientes sobretudo pelas folhas, pois suas raízes representam meros órgãos de fixação. Quando morrem, suas folhas se acumulam no solo onde são decompostas, liberando os nutrientes absorvidos ao resto da vegetação. Este processo favorece também a consolidação do solo e a retenção de água, permitindo sua colonização por novas espécies. Quando áreas previamente ocupadas por bromélias são colonizadas por espécies arbustivas e arbóreas, elas passam a crescer sobre as copas para evitar a competição por luz. Talvez seja este um dos principais mecanismos responsáveis pelo desenvolvimento da vegetação nos ecossistemas de restinga. 
O papel da fauna nos ecossistemas de restinga é pouco conhecido. Como já foi citado anteriormente, a fauna forma uma cadeia alimentar ao longo da qual flui a energia, introduzida no ambiente pelas plantas. A fauna também toma um papel importante na ciclagem de nutrientes através da deposição de fezes no solo e da decomposição dos indivíduos mortos. Além disso, muitos animais são também responsáveis pela reprodução das plantas (polinização) e pela sua dispersão no ambiente através do transporte de frutos e sementes. Nas restingas, no entanto, não conhecemos a importância relativa destes papéis em cada comunidade nem os principais grupos animais envolvidos. Tanto a variedade de tipos de vegetação como a produção de flores e frutos durante o ano todo favorecem a presença de uma fauna bastante diversificada.

\section{RESTINGA E URBANIZAÇĀO}

Como ecossistema litorâneo, a restinga foi um dos primeiros ambientes a sofrer intervenção antrópica desde a época do descobrimento. Na verdade, a utilização das restingas remonta aos tempos pré-históricos e as montanhas de restos de conchas e ossos de peixes (sambaquis), hoje encontrados no litoral, são seu testemunho. Mas sem dúvida que, com a chegada dos exploradores europeus, a exploração dos recursos naturais das restingas tomou vulto, através da derrubada de grandes extensões de mata. A exploração de madeira para construção e mais recentemente para produção de lenha, a utilização do solo para fins agrícolas ou pecuários, a extração de areia e de turfa, o uso de veículos e a utilização da área como aterro de lixo são exemplos de algumas formas de degradação deste ecossistema.

Como forma de intervenção humana, a urbanização é aquela cujos efeitos são mais deletérios, pois muitas vezes age diretamente na eliminação do ecossistema e não somente na sua degradação. Uma prática constante na abertura de novos loteamentos no litoral do Brasil, por exemplo, é a eliminaçāo total da mata no local do loteamento para a demarcação dos terrenos e das ruas e, somente após a construção das casas, é que há um ajardinamento do local, feito geralmente com plantas exóticas.

A eliminação de um ecossistema é acompanhado do empobrecimento da biodiversidade, com a possível extinção de espécies. No caso das restingas, pode haver a diminuiçāo do próprio valor econômico do empreendimento, pois a ausência da vegetação causa desestabilização do solo (essencialmente arenoso), provocando bloqueio de estradas e invasão das habitaçōes pela areia, além do assoreamento de lagoas e canais. As construções à beira-mar, sem a proteção da vegetação, ficam diretamente expostas ao vento e à maresia. Por outro lado, a 
cobertura vegetal contribui ainda para manter a permeabilidade do solo, permitindo que as águas de chuva alimentem o lençol freático, cujo nível garante o fornecimento de água potável na região.

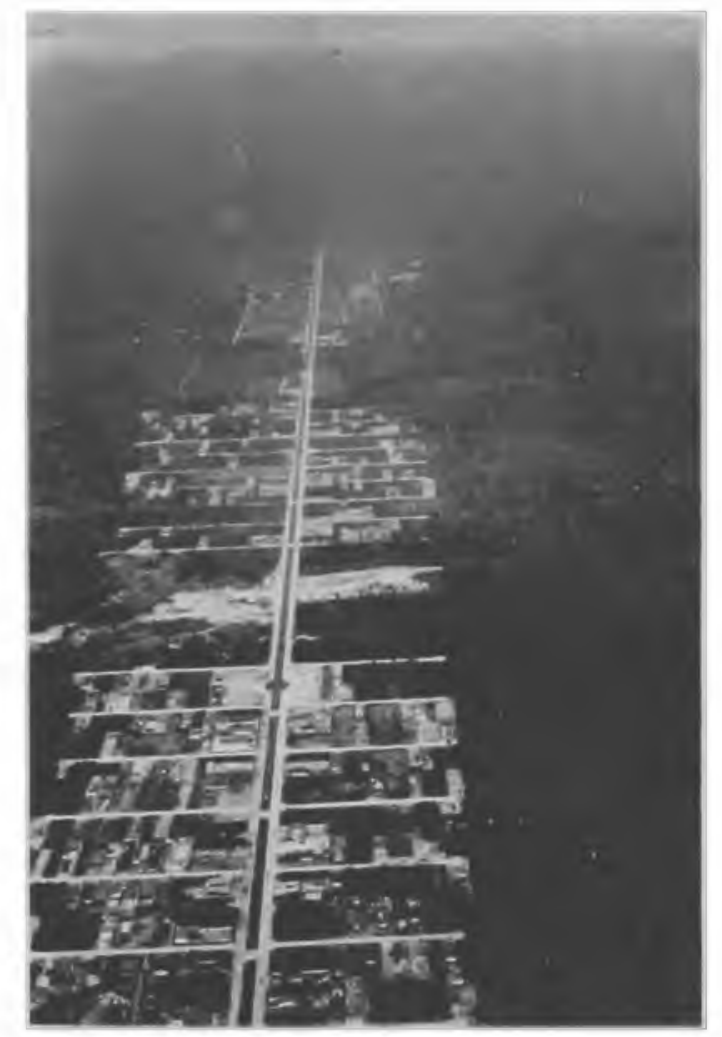

Fig. 7 - Loteamento em Bertioga, SP inserido em uma área de restinga

As restingas de hoje já não são as florestas descritas por naturalistas e cronistas, a maioria estrangeiros, que aqui estiveram entre os sécs. XVI e XIX. Atualmente, a vegetação de restinga está reduzida a pequenas manchas remanescentes e a situação de sua fauna parece ser ainda pior. Por outro lado, em muitos locais estas manchas constituem ainda ambientes bastante diversificados que valeria à pena preservar, mas que estão altamente ameaçados pela especulação imobiliária.

Para uma real preservação dos ecossistemas de restinga seria imprescindível a demarcação de reservas, com uso bastante controlado e que incluíssem toda a diversidade das comunidades presentes neste sistema, as quais foram descritas anteriormente.

Nas outras áreas, a serem urbanizadas, deveria estar prevista a manutenção de manchas significativas do ecossistema. Os espaços verdes dentro da malha urbana têm a função de suavizar a aparência das cidades, modificar o seu microclima e prover locais de lazer e educação. Além destas funções, Dickman (1987) verificou que a existência destes espaços verdes constitui um importante instru- 
mento de preservação da fauna silvestre, na Inglaterra. Quando próximos a outras áreas mais preservadas, eles fazem o papel de corredores para o deslocamento dos animais, permitindo que eles utilizem uma área maior para procurar alimento e parceiros sexuais. Através destes corredores a fauna também pode ter um papel atuante na polinização e dispersão das sementes das plantas.

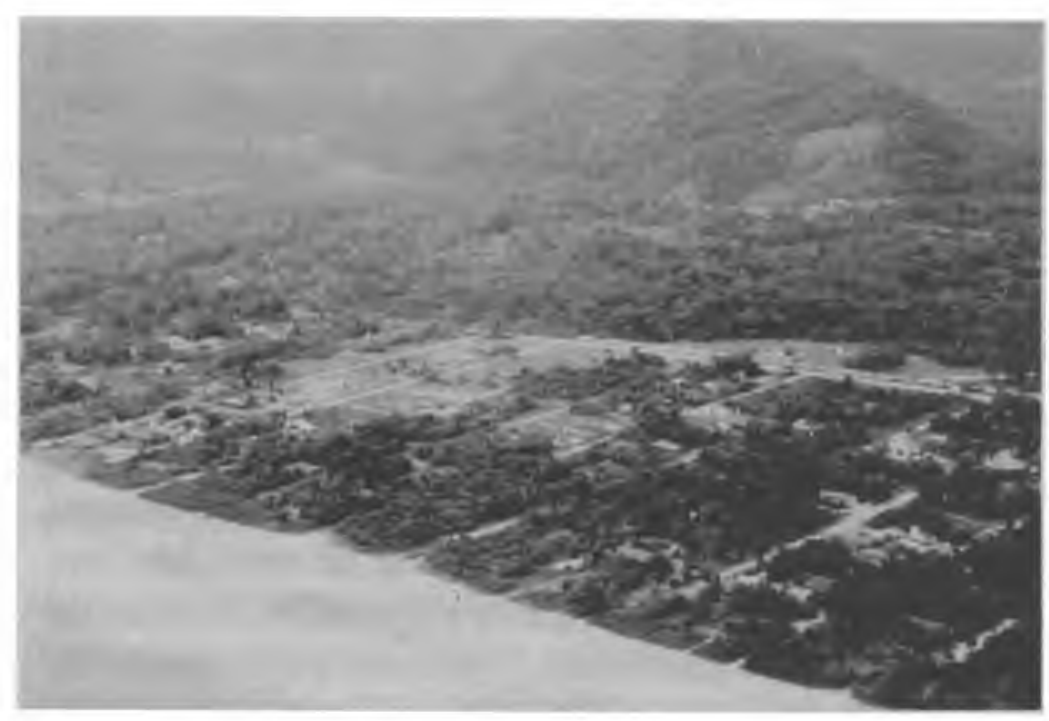

Fig. 8 - Manchas de restinga associadas a loteamento em Ubatuba, SP

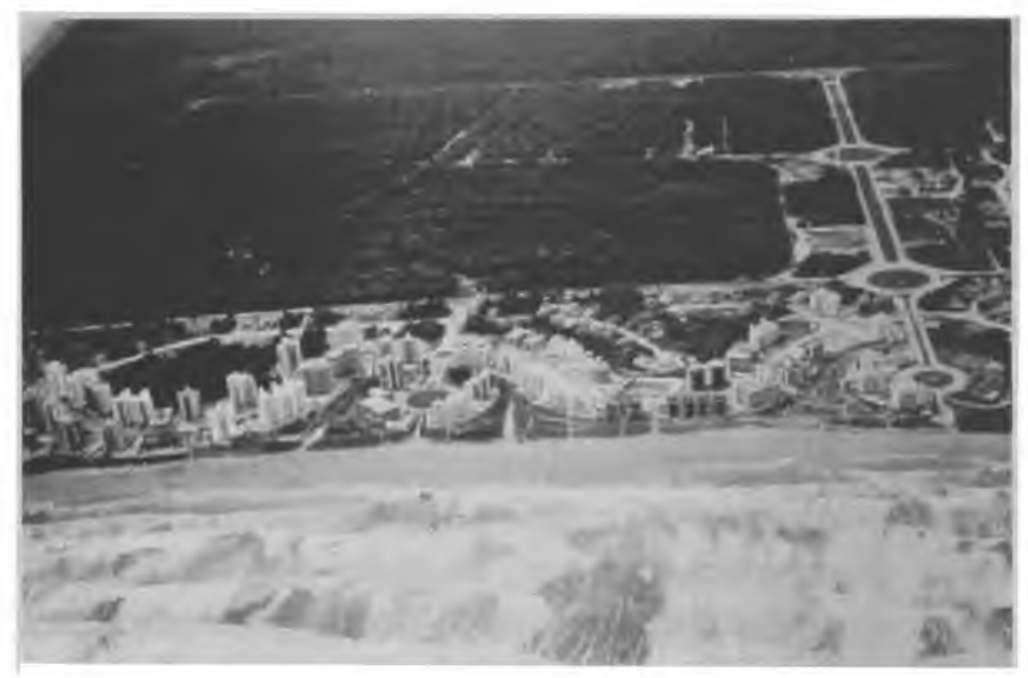

Fig. 9 - Loteamento em Bertioga - SP com alteração da vegetação e a restinga ainda preservada fora da área do loteamento

O estabelecimento de corredores pode ser feito através da utilização da vegetação local no ajardinamento dos terrenos. Espécies da família das mirtáceas, muito comuns nas restingas, apresentam flores brancas e perfumadas. Orquídeas e bromélias fazem parte de duas das seis famílias de plantas mais encontradas em qualquer sistema de restinga estudado no Brasil. Cactáceas com ar- 
quiteturas das mais variadas e flores coloridas e bastante atraentes são também típicas da vegetação de restinga. Estas plantas são geralmente consideradas como o possuidoras de alto potencial ornamental e caberia aos paisagistas melhor pesquisá-las e utilizá-las.

Neste ponto, é necessário frisar que o valor ornamental e mesmo paisagístico de um ambiente é fruto da cultura da população que o avalia e em nossa cultura costuma-se valorizar gramados e palmeiras, mesmo que eles não tenham relação com o resto do ambiente onde serão inseridos (Macedo, 1993). A manutenção deste "verde artificial" implantado em uma restinga, por exemplo, pode tornar-se extremamente cara, pois a grama não tem as adaptações necessárias para enfrentar um solo arenoso e seco e, muitas vezes, a palmeira utilizada não é aquela encontrada na própria restinga, mas sim uma espécie cultivada não adaptada.

A existência do forte gradiente ambiental perpendicular em relação à costa sugere a necessidade de preservação deste gradiente, na förma de manchas verdes com esta orientação predominante. Já foi dito que a vegetação depende da mạresia trazida pelos ventos como fonte de nutrientes. Portanto, a construção de casas ou prédios à beira-mar, que atuam como obstáculo ao vento, podem prejudicar qualquer mancha de vegetação que se queira preservar atrás deste obstáculo.

Por outro lado, a preservação do gradiente permite, por conseqüência, a preservação de uma maior diversidade de ambientes como as dunas próximas à praia, os brejos, as lagoas e a floresta interior, promovendo assim maiores possibilidades de lazer (caminhadas, pesca, observação de aves, etc.). A preservação das dunas costeiras dá ao freqüentador da praia uma sensação de estar em um lugar selvagem e, nos tempos "ecológicos" atuais isto significa um maior valor turístico para a região.

Durante o processo de urbanização, ocorre necessariamente a fragmentação do ecossistema com a formação de manchas verdes de diferentes formas, tamanhos e graus de isolamento. O estudo de ecologia de ilhas, às quais estas manchas verdes poderiam ser comparadas, mostrou que o aumento do tamanho da ilha geralmente está acompanhado de uma maior variabilidade de ambientes e da quantidade de recursos em seu interior, diminuindo a probabilidade de extinção de espécies.

As populações animais necessitam de uma área de vida mínima onde encontrem recursos para sua sobrevivência e reprodução (alimento, moradia, local apropriado para procriação, etc). Este tamanho mínimo varia de espécie para espécie e está geralmente associado a sua posição na cadeia alimentar, isto é, os herbívoros geralmente necessitam de menor área do que os carnívoros no final 
da cadeia alimentar. Uma área grande também permite a sobrevivência de uma população numerosa que é essencial para evitar os efeitos genéticos deletérios do cruzamento contínuo entre poucos indivíduos. Estas considerações são válidas quando o objetivo maior da mancha verde é a manutenção da diversidade e, mesmo assim, existe ainda uma controvérsia entre os pesquisadores sobre o fato de que uma grande reserva seja mais adequada a este fim do que várias pequenas reservas de área total equivalente (Wilcox, Murphy, 1985). No caso urbano, onde as manchas verdes adquirem outras funções além da preservação da vida silvestre, todas as possibilidades de manutenção da cobertura vegetal devem ser levadas em conta.

Ainda em relação à teoria de ilhas, verifica-se que o isolamento da ilha (ou mancha verde) determina a taxa de colonização da mesma, isto é, ilhas mais próximas da fonte de espécies serão mais facilmente colonizadas por novas espécies, aumentando sua diversidade, ou serão mais facilmente recolonizadas pelas espécies que eventualmente sofreram extinção local na ilha.

Já a forma que a mancha verde apresenta parece ser mais importante no caso de manchas pequenas onde a relação perímetro/área é maior. Quanto maior o perímetro em relação à área, maior também será o contato da mancha com o ambiente urbano e somente algumas espécies sobrevivem nestas condições. Uma menor relação perímetro/área implica numa grande extensão interna da mancha verde com condições mais naturais, o que permite a manutenção da diversidade de espécies original da mancha. A forma circular é a que minimiza esta relação perímetro/área e deve ser privilegiada em manchas pequenas.

Com relação a este aspecto, ainda, Goldstein et al. (1981) verificaram que a tendência histórica de dividir os loteamentos em lotes retangulares fez com que as manchas de vegetação eventualmente preservadas fossem pequenas e sujeitas à intervenção humana. Os mesmos autores propõem um desenho hexagonal para os loteamentos onde os lotes seriam fatias triangulares do hexágono e uma mancha verde circular poderia ser mantida no centro do hexágono, isto é, nos fundos de cada terreno. Este modelo, entretanto, também apresenta falhas. No caso das restingas, ele não permitiria a manutenção do gradiente ambiental perpendicular à praia e também não leva em conta o comportamento de nosso povo de colocar cercas ou muros em torno das propriedades, o quê causaria fragmentação da mancha verde, além de uma grande intervenção no centro da mancha, no local de encontro das cercas.

Não poderíamos apresentar aqui o modelo ideal de urbanização de uma restinga, pois ele sempre deverá levar em conta aspectos específicos do local onde será implementado, tais como tipo de solo, drenagem, inclinação do terreno, proximidade à praia, tipo específico de vegetação, expectativa de uso por parte 
dos futuros moradores, etc. Por isso apresentamos tão somente posturas gerais que devem ser observadas na concepção de um modelo básico geral.

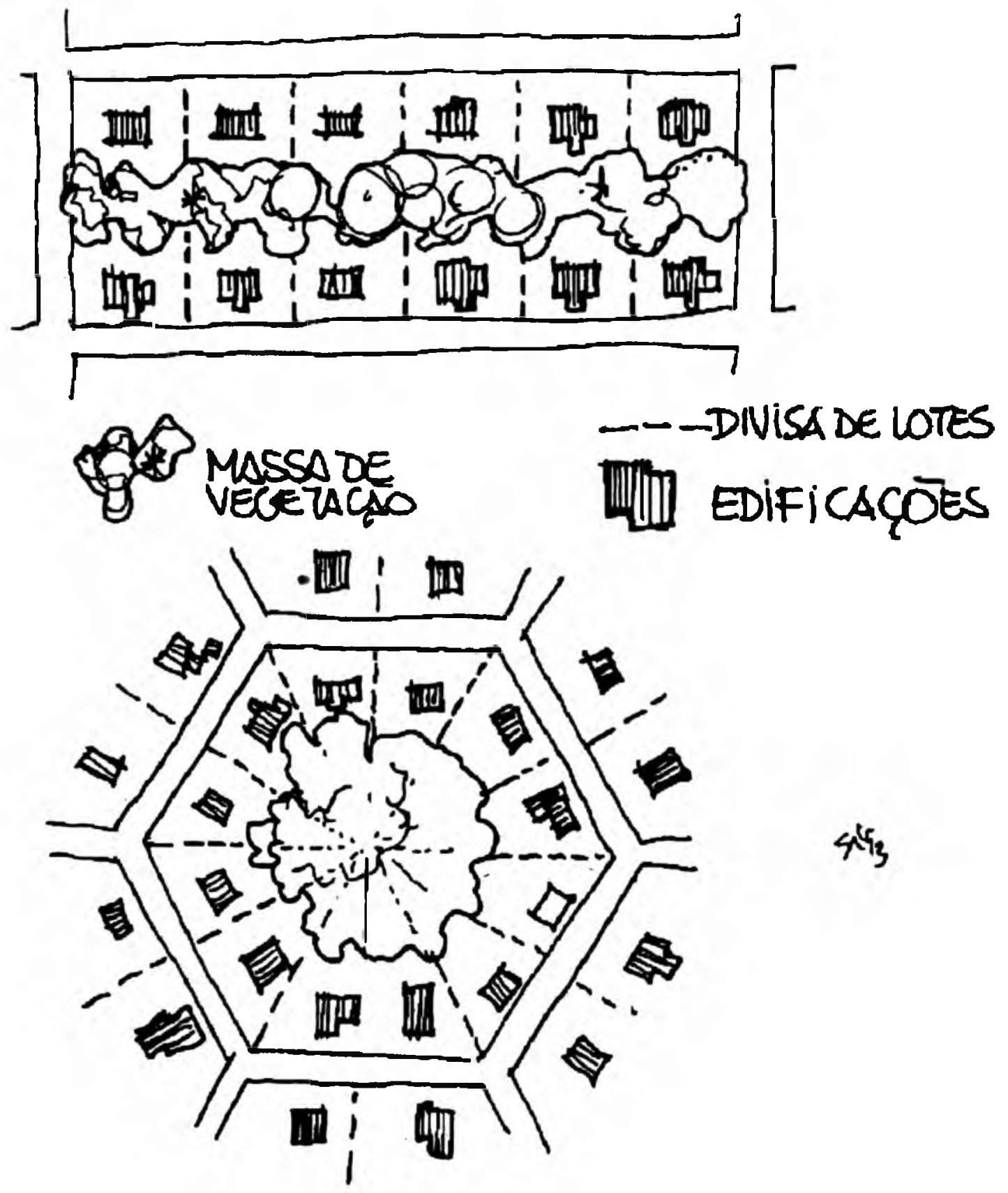

Fig. 10 - Duas propostas de loteamento: a primeira retangular, tradicional que impede a conservação de manchas significativas de vegetação; a segunda hexagonal, onde a manutenção da vegetação nos fundos do terreno forma manchas circulares mais protegidas da intervenção humana (segundo Goldstein et al., 1981) 
Em resumo, os ecossistemas só podem ser preservados de uma maneira integral através da criação de unidades de conservação destinadas a este fim, isto é, áreas onde a intervenção antrópica seja mínima e constantemente monitorada. No entanto, mesmo em locais urbanizados, um determinado nível de preservação ambiental pode ser alcançado através do respeito a certas normas:

1. Modificação do desenho dos loteamentos de modo a diminuir a fragmentação do ecossistema;

2. manutenção de manchas da cobertura vegetal original, maiores e o mais próximas possível umas das outras de modo a se formarem corredores de dispersão e deslocamento para as espécies;

3. utilização de plantas nativas na ornamentação urbana e nos jardins das casas.

Estes cuidados são importantes porque, além da preservação da biodiversidade, revertem em uma maior qualidade ambiental acompanhada da valorização econômica do local, são fonte de educação e lazer para a população e podem evitar gastos desnecessários de energia e dinheiro na recuperação do ambiente.

\section{AGRADECIMENTOS}

Este trabalho resultou de vários convites do Dr. Silvio Soares Macedo para participar de proveitosas discussōes sobre meio ambiente e urbanização, tanto com sua equipe de pesquisa como com alunos em cursos de pós-graduação. Agradeço também a Ligia M. da Rocha, Fernando M. Franco e Luiz de Campos Jr. pela leitura e diversas sugestões ao manuscrito inicial e ao Dr. Silvio S. Macedo pelas fotografias que me foram gentilmente cedidas.

\section{BIBLIOGRAFIA}

ANDRADE, M. A. B. Contribuição ao conhecimento da ecologia das dunas do litoral do estado de São Paulo. Bol. Fac. Filos. Ciên. Letr. Univ. S. Paulo (Botânica), n. 22, p. 3-170, 1967.

ANDRADE, M. A. B.; LAMBERTI, A. A. A Baixada Santista Aspectos Geográficos. São Paulo: EDUSP, 1965.

BLOUIN, M. S.; CONNOR, E. F. Is there a best shape for nature reserves? Biol. Conserv. n. 32, p. 277-288, 1985. 
DICKMAN, C. R. Habitat fragmentation and vertebrate species richness in an urban environment. J. Appl. Ecol. n. 24, p. 337-351, 1987.

FAETH, S. H.; KANE, T. C. Urban Biogeography: city parks as islands for Diptera and Coleoptera. Ecologia. n. 32, p. 127-133, 1978.

Glossário de Ecologia 1987. Publicaçāo ACIESP. n. 57, p. 1-271.

GOLDSTEIN, E. L.; GROSS, M.; DEGRAAF, R. M. Explorations in bird-land geometry. Urban Ecology. n. 5, p. 113-124, 1981.

GOLDSTEIN-GOLDING, E. L. The ecology and structure of urban greenspaces. In: Bell, S.S.: McCoy, E.D.; MUSHINSKY, H.R. (eds.) Habitat Structure the physical arrangement of objects in space. London: Chapman and Hall, p. 392$411,1991$.

HUECK, K. Plantas e formação organogênica das dunas no litoral paulista. parte I. Inst. Botânica, Secretaria da Agricultura do Estado de São Paulo, 1955.

LACERDA, L. D.; ARAUJO, D. S. D.; CERQUEIRA, R.; TURCQ, B. (Eds.) Restingas: Origem, Estrutura e Processos. Rio de Janeiro: Universidade Fed. Fluminense, CEUFF, 1984.

LACERDA, L. D.; ARAUJO, D. S. D. A natureza das restingas. Ciência Hoje 6. n. 33, p. $42-48,1987$.

LOVELOCK, J. E. Gaia: a new look at life on Earth. New York: Oxford University Press, 1979, $157 \mathrm{p}$.

LOVELOCK, J. E.; MARGULIS, L. Atmospheric homeostasis by and for the biosphere: The Gaia Hypothesis. Tellus. n. 26, p. 1-10, 1973.

MACEDO, S. S. Paisagem, Urbanização e Litoral Do éden à cidade. São Paulo, 1993. Tese (Livre-Docência) - FAUUSP.

MARGULIS, L.; LOVELOCK, J. E. Biological modulations of the earth's atmosphere, Icarus. n. 21, p. 471-489, 1974.

MARGULIS, L.; LOVELOCK, J. E. The atmosphere as circulatory system of the biosphere - The Gaia Hypothesis. Coevolution Quaterly, Summer, 1975.

ODUM, E. P. Ecologia. Rio de Janeiro: Interamericana, 1985, 434 p. 
RICKLEFS, R. E. The Economy of Nature. A textbook in basic ecology. Chiron press, Portland, Oregon, 1976, 455 p.

SOULE, M. E.; SIMBERLOFF, D. What do genetics and ecology tell us about the design of nature reserves? Biol. Conserv. n. 35, p. 19-40, 1986.

SOULE, M. E.; WILCOX, B. A. (Eds.). Conservation Biology. An evolutionaryecological perspective. Massachusetts: Sinauer Associates, Inc., Sunderland, $1980,395 \mathrm{p}$.

WHITTAKER, R. H. Communities and Ecosystems. London: The Macmillan Company, $1970,158 \mathrm{p}$.

WILCOX, B. A.; MURPHY, D. D. Conservation strategy: the effects of fragmentation on extinction. Am. Nat. n. 125, p. 879-887, 1985. 